\title{
The Electrocardiographic Leads for Telemetering as Evaluated from View Point of the Transfer Impedance Vector
}

\author{
Yoshihisa Nagata, M.D.
}

\section{SUMMARY}

(1) From the torso model experiments, the measurements of the transfer impedance vectors were carried out for the conventional 12 leads, Frank's lead system and the following 6 different leads commonly used for the ECG-telemetering such as $\mathrm{V}_{5 \mathrm{R}}-\mathrm{V}_{1} \sim \mathrm{V}_{9}$ leads, EEP leads, $\mathrm{C}_{5}-\mathrm{M}$ lead, $\mathrm{L}_{1}-\mathrm{ST}_{1}$ and $\mathrm{L}_{1}-\mathrm{TH}_{1}$ lead, when the current dipole was placed in turn at 27 points within the space occupied by the heart in the human torso model filled with electrolyte solution. The transfer impedance vectors for all leads above-mentioned werc compared to each other.

(2) $V_{5 R^{-}}-V_{1} \sim V_{9}$ leads can be used for the ECG-telemetering, as the equivalent to the precordial leads $V_{1} \sim V_{9} . \quad C_{5}-M, E E P-C_{5}$ and $V_{5 R^{-}}-V_{5}$ lead could be equivalent to the precordial lead $V_{5}$, and $L_{1}-S T_{1}$ and $L_{1}-T_{1}$ lead were equivalent to the augmented unipolar limb lead $a V_{F}$.

(3) Taking into account of the experimental result, the number of electrodes applicable and the possibility to eliminate the interference of muscle potential, $\mathrm{C}_{5}-\mathrm{M}, \mathrm{V}_{5 \mathrm{R}}-\mathrm{V}_{5}$ and $\mathrm{L}_{1}-\mathrm{TH}_{1}$ lead can be considered to be the most sensitive leads for detecting coronary artery disease in latent form.

\section{Additional Indexing Words :}

Cardiac electromotive force Lead vector Heart vector Human torso model Artificial current dipole

$7 \mathrm{HE}$ bio-medical telemetering, which is a means of the recording the important electrophysiological informations of the human subjects during physical exercise or in remote, is applied largely in the field of medicine. Many reports upon the practical application of electrocardiographic telemetering have been presented, but the reports on the basic investigation have been very few and further investigation will be necessary for the development of the method and technique in its telemetering. The one of the main purposes of the ECG-telemetering is to find out any change of the electrical activity of the heart during the physical exercise of the human subjects. Therefore, it is necessary for the ECG-telemetering that the electrodes applied on the body

From the Division of Circulation and Respiration, the Research Institute of Environmental Medicine, Nagoya University, Nagoya.

Received for publication September 8, 1969. 
surface should be less in number and the lead system should possess lesser degree of signal-to-noise ratio if technically possible, namely the avoidance of interference by muscle potentials and furthermore it is hoped that any lead system can more faithfully record the ST-T changes in electrocardiogram. The purpose of this investigation was to evaluate the superiority and validity among the 6 different lead systems currently used for the EGG-telemetering, based on the results derived from the analysis of the transfer impedance vectors.

\section{Theoretical Principle}

Burger and van Milaan ${ }^{11}$ have proposed that the potential difference appearing on any given electrocardiographic lead could be expressed by the scalar product of the heart vector $(\overrightarrow{\mathrm{H}})$ and its relevant lead vector $(\overrightarrow{\mathrm{L}})$. Schmitt ${ }^{2}$ ) has proposed the similar concept, but he has used his term as the transfer impedance vector for the analog of the lead vector. Therefore, it could be considered that the lead vector is essentially same as the transfer impedance vector in the theoretical background.

The unit cardiac electromotive force (E.M.F.) of the infinitesimal small area located at the boundary between the excited and unexcited myocardium is supposed to be represented by equivalent current dipole and this unit of E.M.F. is expressed as $\overrightarrow{\mathrm{H}}_{i}$ in terms of vector quantity, and this E.M.F. vector $\left(\overrightarrow{\mathrm{H}}_{i}\right)$ is expressed as 3 vectorial components on $\mathrm{X}, \mathrm{Y}$ and $\mathrm{Z} 3$ rectangular orthogonal co-ordinates, resulting their magnitudes and directions to be $\mathrm{H}_{\mathrm{x}}^{\mathrm{i}}, \mathrm{H}_{\mathrm{y}}^{\mathrm{i}}$ and $\mathrm{H}_{\mathrm{z}}^{\mathrm{i}}$ respectively.

The transfor impedance vector, electrically mcasured between the location of a given current dipole and arbitrary lead points, is defined as $\overrightarrow{\mathrm{L}_{\mathrm{i}}}$ in terms of vector quantity, and the components of its vector are denoted as $L_{x}^{1}, L_{y}^{1}$ and $L_{z}^{i}$ in the similar fashion as the E.M.F. vector is defined.

In this situation above-mentioned, an electrical potential difference $\left(V_{i}\right)$ at a given lead point based upon such single E.M.F. of the unit area will be expressed as follows:

$$
\mathrm{V}_{1}=\overrightarrow{\mathrm{H}}_{\mathrm{i}} \cdot \overrightarrow{\mathrm{L}}_{\mathrm{i}}=-\mathrm{H}_{\mathrm{x}}^{1} \cdot \mathrm{L}_{\mathrm{x}}^{1}+\mathrm{H}_{\mathrm{y}}^{1} \cdot \mathrm{L}_{\mathrm{y}}^{1}+\mathrm{H}_{z}^{1} \cdot \mathrm{L}_{z}^{1}
$$

Based on the electrical principle of superposition, the electrical potential difference appearing in a given lead is obtained by summing up all of the individual electrical potential difference deriving from the every elementary unit area.

Namely, it is expressed as follows:

$$
\sum \mathrm{V}_{\mathrm{i}}=\sum \overrightarrow{\mathrm{H}}_{\mathrm{i}} \cdot \overrightarrow{\mathrm{L}_{\mathrm{i}}}=\Sigma\left(\mathrm{H}_{\mathrm{x}}^{1} \cdot \mathrm{L}_{\mathrm{x}}^{\mathrm{1}}+\mathrm{H}_{\mathrm{y}}^{\mathrm{i}} \cdot \mathrm{L}_{\mathrm{y}}^{\mathrm{i}}+\mathrm{H}_{\mathrm{x}}^{\mathrm{i}} \cdot \mathrm{L}_{\mathrm{z}}^{\mathrm{i}}\right)
$$

Thereupon, in case that if the heart vector (the summation of all of the E.M.F. vector) will possess some direction and magnitude, the potential difference appearing on any given lead will be determined by the direction and magnitude of the transfer impedance vector.

It can be rationally conceivable that the identical electrocardiographic patterns could be recorded, when 2 different lead systems possess the same lead vector each other, even in the case of different locations of electrodes anatomically on the body surface. 
On the basis of the above stated facts, the suitability of any lead systems useful for the ECG-telemetering can be evaluated theoretically from the analysis of the transfer impedance vector.

\section{METHOD}

1. The measurements of the transfer impedance vectors were carried out for the following lead systems

i) Frank's X, Y and Z lead

ii) Unipolar limb lead $\left(\mathrm{V}_{\mathrm{R}}, \mathrm{V}_{\mathrm{I}}\right.$, and $\left.\mathrm{V}_{\mathrm{F}}\right)$

iii) Precordial lead $\left(V_{1}\right.$ to $\left.V_{6}\right)$

iv) Ear-Ensiform-Precordial (E--E-P) lead proposed by LaDue ct al. ${ }^{3 \text { ? }}$

The central terminal composed from 3 electrodes located at the right ear, the ensiform process and any point on precordium, based on the similar idea of Wilson's central terminal. The potential difference was obtained between this central terminal and each of the exploring precordial lead points $\mathrm{C}_{4}, \mathrm{C}_{5}$ and $\mathrm{C}_{6}$.

v) Nehb's " $A$ ", " $D$ " and " $J$ " lead"

" $A$ " lead in bipolar nature consists of 1 electrode for negative pole placed at the second intercostal space at the junction of the right sternal border and the other for positive pole placed at the point of cardiac apex beat on the thorax, and "D" lead between the negative pole at the second intercostal space at the junction of the right sternal border and positive pole at the point on the posterior axillary line at the same level of apex beat, and " $\mathrm{J}$ " lead between the negative pole at the point on the posterior axillary line at the same level of apex beat and the positive pole at the point of apex beat.

vi) $\mathrm{C}_{5}-\mathrm{M}$ lead used by Craige et al. ${ }^{5)}$ and Blackburn et al. ${ }^{6)}$

This lead consists of the negative pole at the upper margin of manubrium sterni and of the positive pole at the point on the anterior axillary line at the level of the fifth intercostal space.

vii) $\mathrm{V}_{5 \mathrm{R}}-\mathrm{V}_{1} \sim \mathrm{V}_{9}\left(\mathrm{C}_{5 \mathrm{R}}-\mathrm{C}_{1} \sim \mathrm{C}_{9}\right)$ leads used by Gilson et al., ${ }^{7)}$ Bellet et al. ${ }^{8)}$ and Takagi ct al. ${ }^{10}$ )

These leads consist of 1 electrode for negative pole at the point on the right anterior axillary line on the level of the fifth intercostal space and of the other for positive pole at each of the left hemithoracic lead points $V_{1}$ to $V_{9}$.

viii) $\mathrm{L}_{1}-\mathrm{ST}_{1}$ and $\mathrm{L}_{1}-\mathrm{TH}_{1}$ lead proposed by Kobayashi et al. ${ }^{11}$

These leads consist of 1 electrode placed at the left side of the first lumbar vertebra and of the other placed at the point on the first intercostal space at the junction of the left sternal border, or at the point on the left side of the first thoracic vertebra respectively.

\section{The measurement of the transfer impedance vector (Fig. 1)}

The human torso model previously reported ${ }^{12)}$ was filled with $0.1 \%$ saline solution with its conductivity of $383 \mathrm{ohm}-\mathrm{cm}$. at $25^{\circ} \mathrm{C}$. The artificial current dipole was inserted into the torso model and placed in turn at 27 points, which sufficiently covered the space usually occupied by the heart within the human torso model, as the orthogonal direction ( $\mathrm{X}, \mathrm{Y}$ and $\mathrm{Z}$ axes) of the dipole could coincide with the anatomical orthogonality of the torso model. Then, the dipole was energized with a unit strength current of $4.0 \mathrm{~mA}$. in sinusoidal wave at $100 \mathrm{H}_{2}$ per sec, through the 


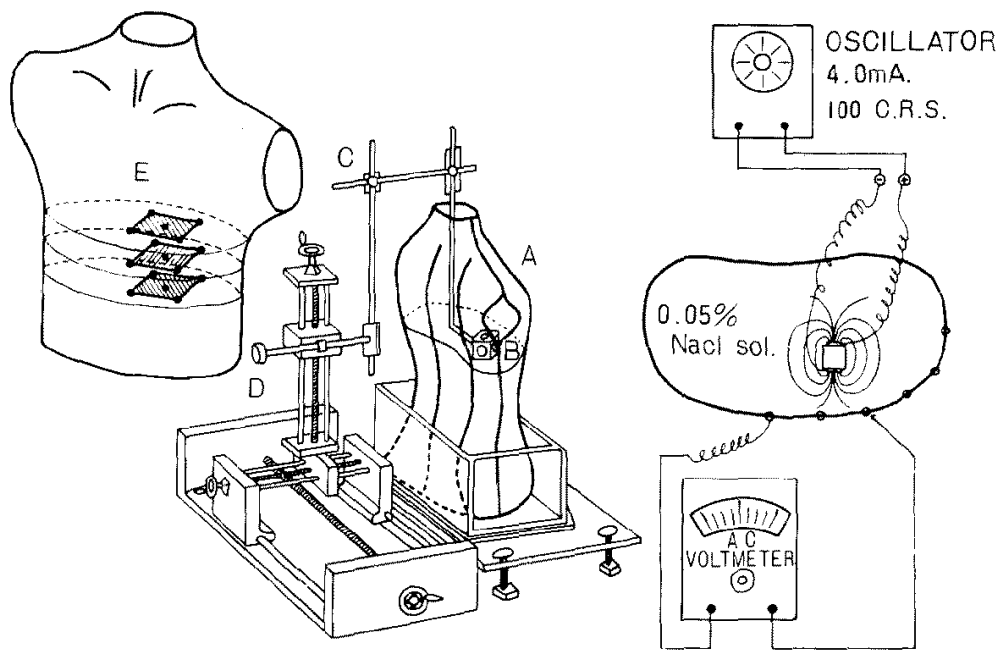

Fig. 1. Schematic illustration of experimental set-up.
A : human torso model
B : three directional current dipole
C: dipole-assembly
D : three way cathetometer fo setting
E: dipole location within the human torso model the dipole at the desired location

oscillater (Hewlett-Packard model 204B) in 3 orthogonal directions in turn. Then, at every dipole location, the electrical potential difference was measured between the relevant corresponding lead points, and these measured values were considered to be equivalent to the magnitudes and directions of the transfer impedance vectors. This measurement was carried out for each of the ECG-telemetering leads above mentioned and of Frank lead system and of the conventional 12 lead systems. In this study, the polarity of the reference frame $\mathrm{X}, \mathrm{Y}$ and $\mathrm{Z}$ was defined as follows: the left being positive on the left-to-right direction, the caudal direction being positive on the cephalo-caudal direction and the anterior direction being positive on the anteroposterior direction in respect to the anatomical rectangular 3 directions of the human torso model.

\section{Results}

The measurements for the transfer impedance vector were carried out, when the artificial current dipole was placed at each of 27 points in turn.

The representative case, in which the measurement was done when the dipole was placed at the ventricular center, was illustrated in Fig. 2 for the convenience of better understanding of the results obtained from the analysis of the transfer impedance vector of each of all telemetering lead systems under investigation.

The lead systems, which would possess the fairly satisfactory magnitude of the transfer impcdance vector, were $\mathrm{C}_{5}-\mathrm{M}, \mathrm{EEP}-\mathrm{C}_{5}, \mathrm{Nehb}$-" $\mathrm{A}$ " and $\mathrm{V}_{5 \mathrm{R}^{-}}$ 
$\mathrm{V}_{4}, \mathrm{~V}_{5}, \mathrm{~V}_{6}$ for the X-component, $\mathrm{C}_{5}-\mathrm{M}$, Nehb-" $\mathrm{A}$ " and " $\mathrm{J}$ ", $\mathrm{L}_{1}-\mathrm{ST}_{1}, \mathrm{~L}_{1}-\mathrm{TH}_{1}$ for the Y-component, EEP- $\mathrm{C}_{4}, \mathrm{Nchb-}$ " $J$ ", $\mathrm{V}_{5 \mathrm{R}}-\mathrm{V}_{2}, \mathrm{~V}_{3}, \mathrm{~V}_{4}$ for the Z-component (Fig. 2).

The magnitudes of 3 orthogonal components ( $\mathrm{X}, \mathrm{Y}$ and $\mathrm{Z}$ ) of the transfer impedance vectors were compared each other, when the dipole was placed at each of 26 dipole locations in turn, beside at the ventricular center. These results were very similar to those obtained in the case that the dipole was set at the ventricular center.

The magnitudes of the transfer impedance vectors at several dipole location including the ventricular center in turn, were compared each other. Comparative analysis between the lead $V_{5 R^{-}} V_{1} \sim V_{6}$ and the precordial lead $V_{1}$ to $V_{6}$ showed that the magnitudes of 3 orthogonal components ( $X, Y$ and $\mathrm{Z}$ axes) of the transfer impedance vector were in good resemblance each other, as may be seen in Fig. 2 and 3.

The magnitudes and directions of vectorial sum from $\mathrm{X}$ and $\mathrm{Z}$ components of the transfer impedance vector were illustrated for the EEP- $\mathrm{C}_{4}, \mathrm{C}_{5}$ and $\mathrm{C}_{6}$ lead and for the precordial lead $V_{4}, V_{5}$ and $V_{6}$. It was very interesting to note that these leads were very similar to each other in respect to their magnitudes and directions (Fig. 4).

All 3 vector components ( $\mathrm{X}, \mathrm{Y}$ and $\mathrm{Z}$ ) of the tranfer impedance vector
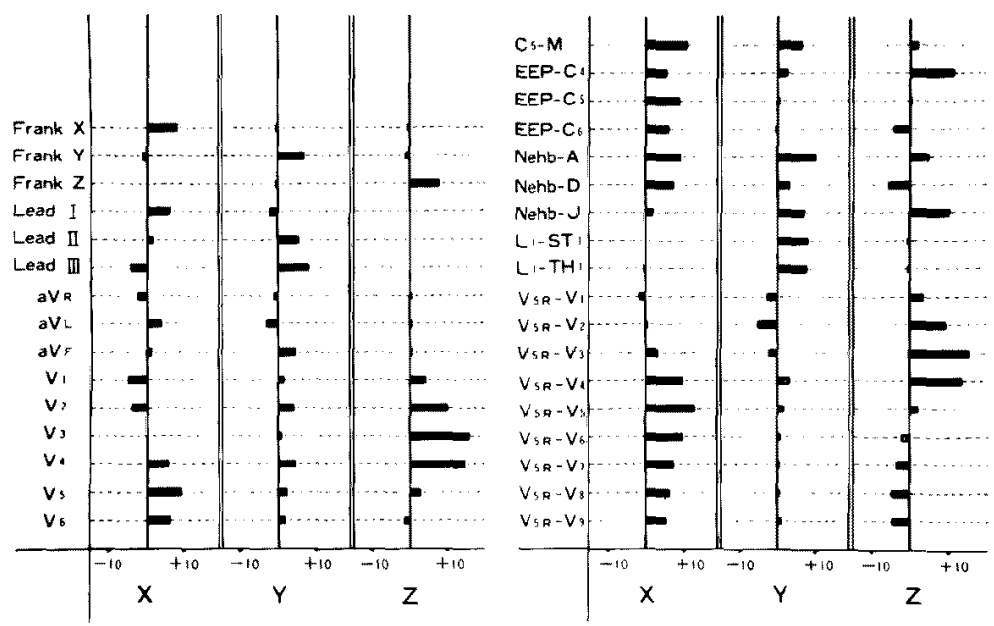

Fig. 2. The magnitudes of three orthogonal components ( $X, Y$ and $Z$ ) of the transfer impedance vectors for various lead's, when the dipole was placed at the ventricular center. The diagram in the left side show the values for the various leads commonly used for recording the resting-EGG, whereas the diagram in the right shows the values for the various leads useful for the ECGtelemetering. The polarity in each diagram was as follows: the right being positive and the left being negative in each component. 


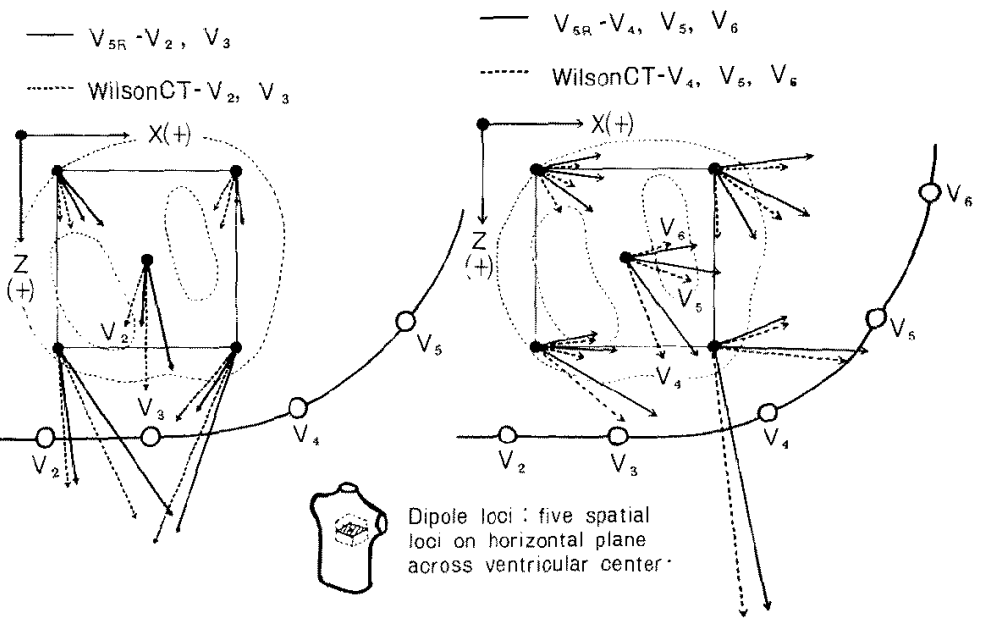

Fig. 3. The magnitudes and directions are illustrated for $\mathrm{X}$ and $\mathrm{Z}$ components of transfer impedance vectors measured for the precordial lead $V_{2}$ and $V_{3}$ shown by interrupted line vectors, the lead $V_{5}-V_{2}$ and $V_{3}$ by solid line vectors at the right in this figure, the precordial lead $V_{4}, V_{5}$ and $V_{6}$ shown by interrupted line vectors, and the lead $V_{5} R_{4}, V_{5}$ and $V_{6}$ shown by solid line vectors at the five spatial loci (indicated by black spots) on the horizontal plane across the ventricular center. The convention was given only for the vectors measured at the ventricular center.

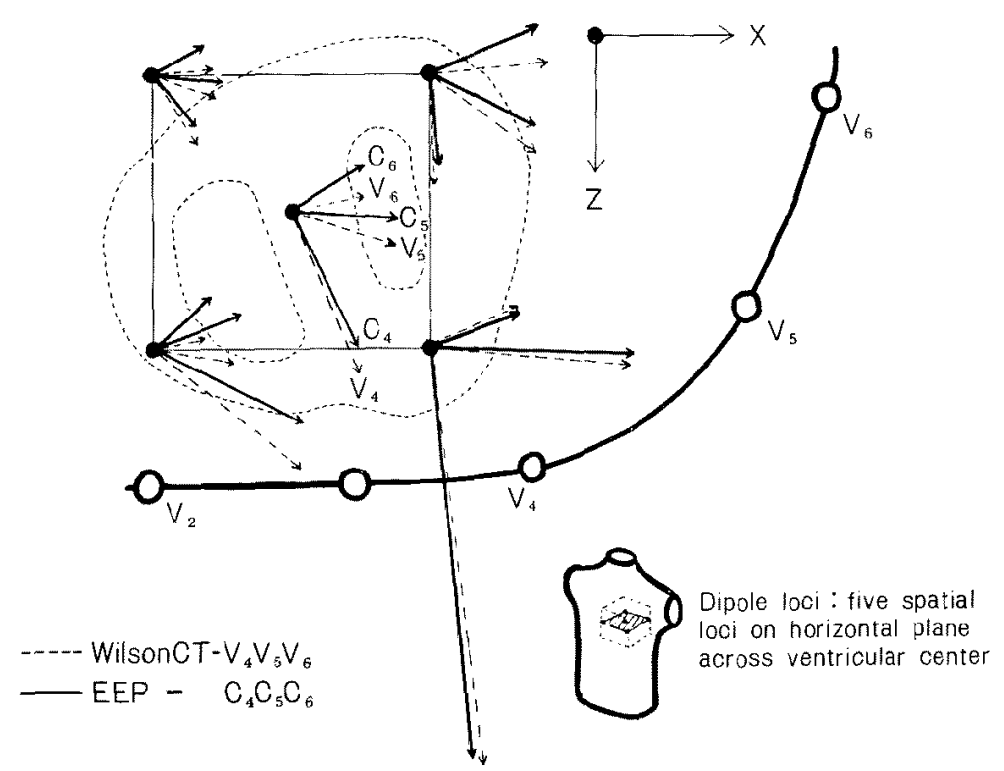

Fig. 4. Transfer impedance vectors measured for the precordial lead $V_{4}$, $V_{5}$ and $V_{8}$ shown by interrupted line vectors and the EEP- $C_{4}, C_{5}$ and $C_{6}$ shown by solid line vectors. The same conventions used as shown in Fig. 3. 


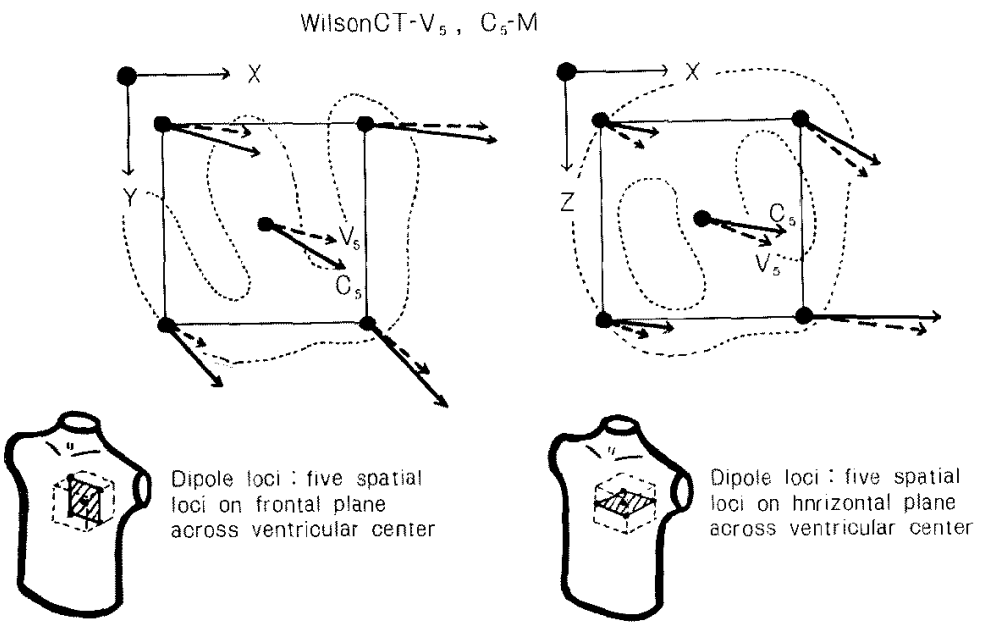

Fig. 5. The frontal components ( $X$ and $Y$ ) and the horizontal components $\left(\mathrm{X}\right.$ and $\mathrm{Z}$ ) of transfer impedance vectors measured for the precordial lead $\mathrm{V}_{5}$ and for the lead $\mathrm{C}_{5}-\mathrm{M}$, when the dipole was placed in turn at five different locations on the frontal plane across the ventricular center (at the left in this figure) and on the horizontal plane across the ventricular center (at the right in this figure).

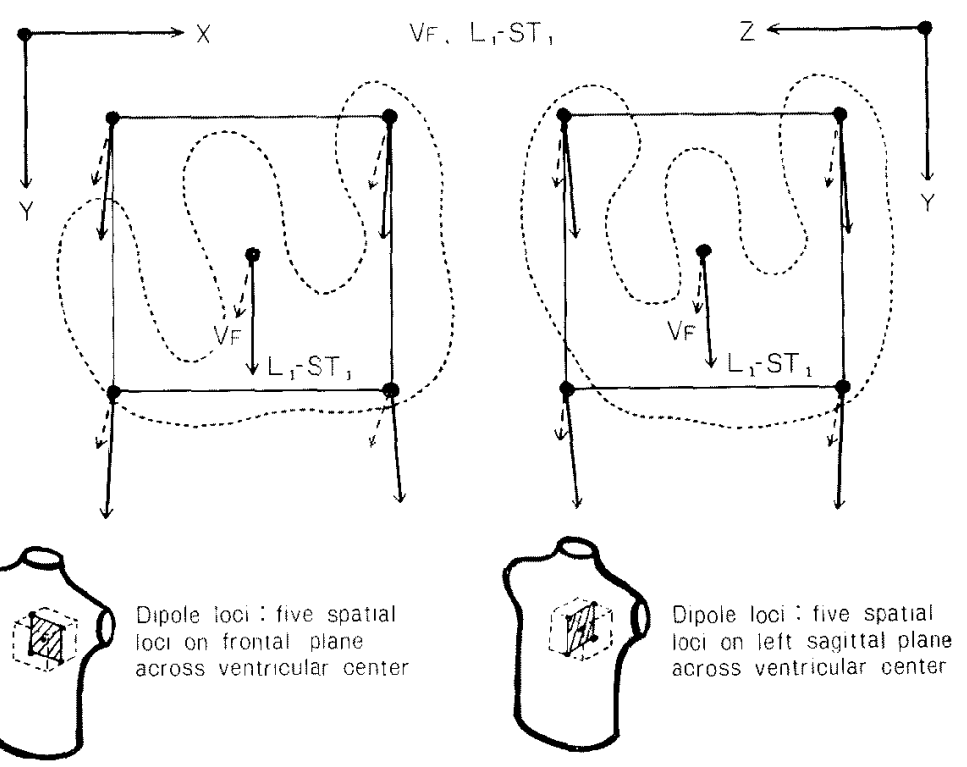

Fig. 6 (a). The frontal ( $\mathrm{X}$ and $\mathrm{Y}$ ) and sagittal ( $\mathrm{Y}$ and $\mathrm{Z}$ ) components of transfer impedance vectors of the unipolar lead $V_{F}$ and the lead $L_{1}-S_{1} T_{1}$ when the dipole was placed in turn at five different locations including ventricular center on the frontal plane (at the left in the figure) and on the left sagittal plane (at the right in the figure). The solid line vector indicates the lead $\mathrm{L}_{1}-\mathrm{ST}_{1}$, whereas the interrupted line vector indicates the unipolar lead $\mathrm{V}_{\mathrm{F}}$. The magnitudes and directions of these vectors were compared each other. 


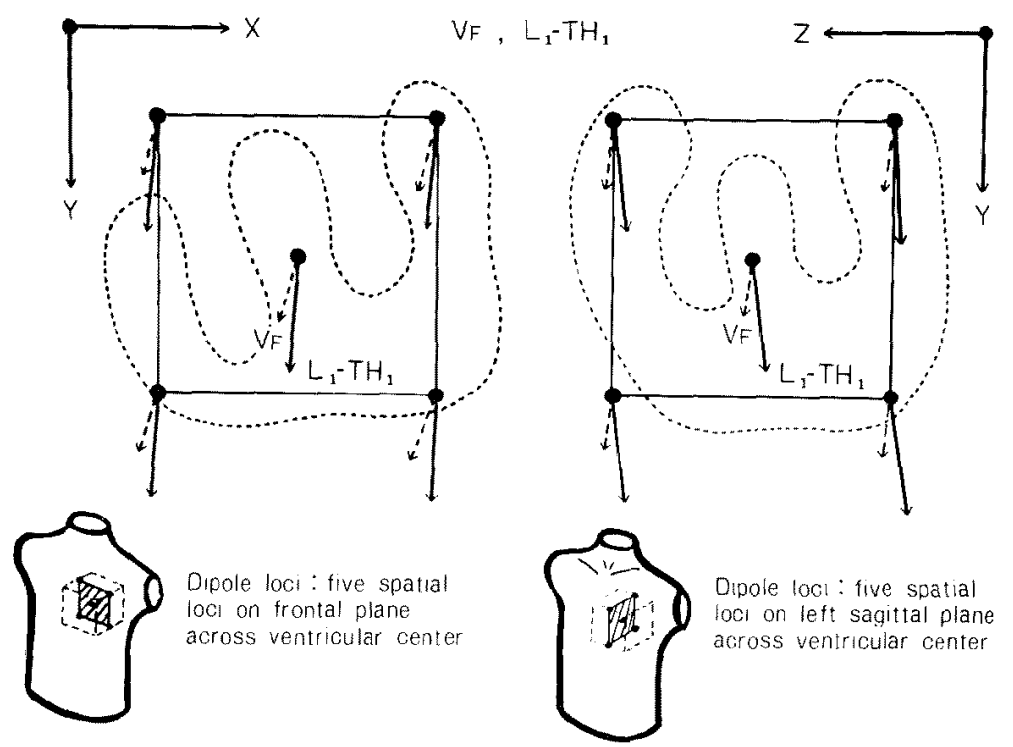

Fig. 6 (b). The frontal ( $\mathrm{X}$ and $\mathrm{Y}$ ) and sagittal ( $\mathrm{Y}$ and $\mathrm{Z}$ ) components of transfer impedance vectors of the unipolar lead $V_{F}$ and the lead $L_{1}-S T_{1}$ when the dipole was placed in turn at five different locations including the point of the ventricular center on the frontal plane (at the left in the figure) and on the left sagittal plane (at the right in the figure). The solid line vector indicates the lead $\mathrm{L}_{1}-\mathrm{TH}_{1}$, whereas the interrupted line vector indicates the unipolar lead $\mathrm{V}_{\mathrm{F}}$.

for $\mathrm{C}_{5}-\mathrm{M}$ lead were in better accordance to those for the precordial $\mathrm{V}_{5}$ lead, as compared with the $V_{5 R}-V_{5}$ lead and EEP-C $C_{5}$ lead, as may be seen in Fig. 5.

The spatial vector composed by the rule of parallerogram from these $\mathrm{X}$, $\mathrm{Y}$ and $\mathrm{Z}$ components of the transfer impedance vector measured for Nehb- " $\mathrm{A}$ " lead was directed to the left inferior anteriorly, in Nehb- "D" lead directed to the left inferior posteriorly, in Nehb- " $\mathrm{J}$ " lead directed to the inferior anteriorly, and all of these leads were noted to possess the fairly satisfactory magnitudes of the transfer impedance vectors.

The vectorial sum calculated from $\mathrm{Y}$ and $\mathrm{Z}$ components of the transfer impedance vector measured for $\mathrm{L}_{1}-\mathrm{ST}_{1}$ and $\mathrm{L}_{1}-\mathrm{TH}_{1}$ lead were approximately parallel to the anatomical cephalo-caudal direction of the torso model ( $\mathbf{Y}$-axis) and to the direction of $\mathrm{Y}$-component in the lead $\mathrm{V}_{\mathrm{F}}$, as shown in Fig. 6(a) and (b).

All results presented above were derived from the analysis of the transfer impedance vectors when the dipole was placed, in turn, at several locations including the ventricular center within the space of the torso model occupied by the heart. However, further studies showed that almost similar results were also obtained when the dipole was displaced at other locations in the vicinity to 
the space occupied by the heart.

\section{Discussion}

The post-exercise electrocardiogram to evaluate coronary reserve, proposed by Master, ${ }^{13), 14}$ ) has been used as the important auxiliary aid to the detection of coronary artery disease, and this method is to record the ECG after the actual period of exercise from the subject resuming in resting supine position. Since the validity of using this post-exercise electrocardiogram has been recognized in the field of cardiology, the further important advent has been made by using the miniature radio-electronics; the radio-electrocardiography proposed by Holter ${ }^{15}$ in 1957, provided a practical method of recording the dynamic EGG changes during the actual period of exercise.

Takahashi and Iwatsuka et al. ${ }^{16)}$ investigated the diagnostic accuracy of the post-exercise ECG and the dynamic-exercise ECG (ECG taken during actual period of exercise) for detection of the ST segment depression in ischemic heart disease, and they concluded that the post-exercise ECG was more useful in that clinical aspect.

On the other hand, Kobayashi et al. ${ }^{11)}$ investigated to find the time relationship in which the maximal change of ST-T deviation appears during and after actual period of exercise, by taking the dynamic-exercise ECG and the post-exercise ECG recorded by the $\mathrm{V}_{5 \mathrm{R}}-\mathrm{V}_{5}$ lead system, and they found that the detection ratio of positive tracing was almost equal; $50 \%$ in the postexercise and the dynamic-exercise $E_{C G}$ in the subject-group displaying the normal resting ECG, however, its ratio is much higher in the dynamic-exercise EGG in the subject-group displaying the resting ECG to be abnormal. The similar results were reported by LaDue et al. ${ }^{31,17)}$ and Bellet et al. ${ }^{81,9 \text {, }}$

From the results above-mentioned, it is rationally suggested that ECGtelemetering could be useful even in the case of the Master's two step test, for the early detection of ischemic heart disease.

For the clinical application of telemetering ECG practically, any lead, of which the electrodes could be firmly contacted to the skin, should be chosen in order to eliminate the muscle potential. For the elimination of muscle potential, it is necessary that the electrode should be applied to the body surface where the body motion is minimal, and should not be applied to any part on all 4 extremities which may provide the interference of muscle potential to the ECG tracing.

Therefore, 6 different lead systems for the EGG-telemetering, in which the electrode positions were restricted to the thoracic surface and forehead, were investigated in the present study. 
Regardless of wire-transmission or wireless-transmission of ECG-signal, the practical value of ECG-telemetering may be evaluated by the possibilities whether ECG-signal can be recorded during actual period of exercise or not, whether the monitoring of ECG-signal supplied from remote distance can be performed for rather long period of time or not. In such condition, number of leads should be limited to 1 or 2 bipolar leads in maximum, and therefore, these leads are naturally required to possess the ability to record the necessary and sufficient parametric informations in ECG-signal.

On the other hand, it is very useful and convenient for the electrocardiographic diagnosis that if the pattern recorded by any lead of ECG-telemetering will closely resemble in configuration to those of conventional 12 leads, and moreover much convenient, if these leads of the ECG-telemetering will possess the excellent capability and sensitivity to register ST-T change more precisely in the case of coronary insufficiency.

From the above-mentioned reasons, it can be advantageous that the magnitude and direction of the transfer impedance vector of any lead for the ECG-telemetering will closely resemble to those of ST-vector ${ }^{18)}$ in general, and to those of conventional 12 leads, for example $V_{\mathrm{L}}, \mathrm{V}_{\mathrm{F}}$ and the precordial lead $V_{1}$ to $V_{6}$ which have been known to be sensitive in registering the ST-T change in resting ECG in the case of coronary artery disease.

As already shown in the part of the result, the precordial leads $V_{1}$ to $V_{6}$ were noted to be closely resembled to the leads $V_{5 R^{-}} V_{1}$ to $V_{6}$ for telemetering use, when these 2 different lead systems were compared to each other in respect to the magnitudes and directions of their transfer impedance vectors. It was reported also by Kobayashi et al. ${ }^{11}$ that these lead systems were in good accordance each other in respect to the pattern and the amplitude of electrocardiogram, as based on the result of analysis on actually recorded ECGs in clinical materials.

Upon the comparison of the precordial leads $V_{4}, V_{5}$ and $V_{6}$ with EEP$\mathrm{C}_{4}, \mathrm{C}_{5}$ and $\mathrm{C}_{6}$ in respect to the transfer impedance vector, the EEP lead system showed the better resemblance than $V_{5 R}-V_{4}, V_{5}$ and $V_{6}$, although EEP lead system has some disadvantage that this system needs more electrodes in number than $V_{5 R}-V_{4}, V_{5}$ and $V_{6}$.

LaDue et al. ${ }^{3)}$ pointed out one of the advantageous aspects that the EEP-central terminal would show approximately same reference potential to the Wilson's central terminal, thus the EEP-C $4, C_{5}$ and $\mathrm{C}_{6}$ system could produce the ECG pattern very closely resembling in configuration to those recorded by the precordial leads $V_{4}, V_{5}$ and $V_{6}$. This point was also verified from the view point of the transfer impedance vector in the present study.

The transfer impedance vector for $\mathrm{C}_{5}-\mathrm{M}$ lead system was directed to the 
left inferior more or less anteriorly, and was in better accordance with that for the precordial lead $V_{5}$, than that for the EEP- $\mathrm{C}_{5}$.

Blackburn et al. ${ }^{6}$ ) proposed that EEP- $\mathrm{C}_{5}$ lead and $\mathrm{C}_{5}$-M lead system were the most sensitive to ST-T change, based upon the result of investigation in which the dynamic-exercise and post-exercise ECGs recorded by several different lead systems for telemetering were compared in respect to the capability to record ST-T change.

In the transfer impedance vectors for Nehb lead systems, its $\mathrm{X}$ and $\mathrm{Y}$ components were noted to possess the fairly satisfactory magnitude in " $\mathrm{A}$ " and " $\mathrm{D}$ " lead, and its $\mathrm{Y}$ and $\mathrm{Z}$ components in " $\mathrm{J}$ " lead, thus these lead systems were considered to be capable to register rather selectively the change of electromotive force occurring at the left-antero-inferior part of the heart.

The magnitudes of the transfer impedance vectors measured for $\mathrm{L}_{1}-\mathrm{ST}_{1}$, $\mathrm{L}_{1}-\mathrm{TH}_{1}$ lead were greater than that of lead $\mathrm{V}_{\mathrm{F}}$, and that of $\mathrm{L}_{1}-\mathrm{TH}_{1}$ lead was slightly larger than that of $\mathrm{L}_{1}-\mathrm{ST}_{1}$ lead. The direction of the transfer impedance vector measured for $\mathrm{L}_{1}-\mathrm{TH}_{1}$ lead was closer to that for $V_{F}$ than that for $\mathrm{L}_{1}-\mathrm{ST}_{1}$ lead. From the viewpoint of the transfer impedance vector, the ECG patterns recorded by both $\mathrm{L}_{1}-\mathrm{ST}_{1}$ and $\mathrm{L}_{1}-\mathrm{TH}_{1}$ lead were considered to be similar to that of lead $V_{\mathrm{F}}$, and $\mathrm{L}_{1}-\mathrm{TH}_{1}$ lead is thought to be superior to $\mathrm{L}_{1}-\mathrm{ST}_{1}$ lead. This superiority of $\mathrm{L}_{1}-\mathrm{TH}_{1}$ lead was also reported by Kobayashi et al., ${ }^{11)}$ as based on the result of analysis on the pattern and amplitude of QRS complex actually recorded from clinical materials.

Yamada et al. ${ }^{19,},{ }^{20)}$ stated that 3 abridged ECG leads $\left(a V_{F}, V_{1}\right.$ and $\left.V_{5}\right)$ were quite adequate and accurate theoretically and clinically for the electrocardiographic screening tests in population mass survey. Therefore, it can be quite convenient if any pattern recorded by some leads for ECG-telemetering will resemble in configuration to those recorded by 3 abridged ECG leads. Especially, it has been known that the effect of physical exercise upon ECG was mainly due to the anoxic change occurring in the left ventricle, when the physical exercise was given to the subject with coronary artery disease. The precordial lead $\mathrm{V}_{5}$, and the augmented unipolar limb lead $a V_{F}$ may register the change of the electromotive force occurring at the left anterior part of the heart and at the infero-posterior part of the heart respectively. Therefore, it may be suitable for ECG-telemetering that any lead, in which the pattern can resemble to those recorded by $\mathrm{V}_{5}$ and $a \mathrm{~V}_{\mathrm{F}}$ lead, can be obtained.

From the above-mentioned reasons, it can be suitable, appropriate and recommended to use $\mathrm{V}_{5 \mathrm{R}}-\mathrm{V}_{5}, \mathrm{EEP}-\mathrm{C}_{5}, \mathrm{C}_{5}-\mathrm{M}$ and $\mathrm{L}_{1}-\mathrm{TH}_{1}$ lead for the ECGtelemetering, which were capable to record the patterns resembling in configuration to that of the precordial lead $V_{5}$ and lead $V_{F}$.

When the condition restricted to only one lead applicable for EGG-tele- 
metering, it can be thought that $\mathrm{C}_{5}-\mathrm{M}$ lead is the most suitable, because of less electrodes used in number and lesser degree of interference of muscle potential. It is also advantageous for easily making diagnosis of coronary artery disease, because this lead will be able to record the greatest degree of ST-T deviation.

\section{ACKNOWLEDGEMENT}

The author sincerely expresses his grateful thanks to Prof. K. Yamada, Assist. Prof. M. Okajima, the Research Institute of Environmental Medicine, Nagoya University, for their interest and guidance for the achievement of this study. The author wishes to thank Dr. N. Okamoto and Dr. T. Kobayashi for their kindest advice during work. Thanks are also extended to all colleagues for their cooperations.

\section{REFERENCES}

1. Burger, H. C. and van Milaan, J. B.: Brit. Heart J. 8: 157, 1946; 9: 154, 1947; 10: 229, 1948.

2. Schmitt, O.H.: Ann. N.Y. Acad. Sci. 65: 1092, 1957.

3. Abarquez, R. F., Freiman, A. H., Reichel, F, and LaDue, J. S.: Circulation 22: 1060, 1960.

4. Nehb, W.: Verh. Dtsch. Ges. Kreislaufforsch. 12: 177, 1939.

5. Gibson, T. C., Thornton, W. E., Algary, W. P., and Graige, E.: New Engl. J. Med. 267 : $1218,1962$.

6. Blackburn, H., Taylaor, H. L., Okamoto, N., Rautahrju, P., Mitchell, P. L., and Kerkhof, A. C.: Physical activity and the heart, edited by Karvonen, M. J. and Barry, A. J., Charles C. Thomas, Illinois, p. 101, 1967.

7. Gilson, J. S. and Griffing, R. B.: Am. J. Cardiol. 8: 212, 1961.

8. Bellet, S., Deliyiannis, S., and Eliakim, M.: Am. J. Cardiol. 8: 385, 1961.

9. Bellet, S., Eliakim, S., Deliyiannis, S., and LaVan, D.: Circulation 25: 5, 1962.

10. Takagi, K., Matsui, S., Kobayashi, M., and Takeuchi, N.: Respiration Circulation 9: 263,1961 (in Japanese).

11. Kobayashi, T., Takeuchi, M., Koro, T., and Tawara, I.: Respiration Circulation 10: 380,1962 (in Japanese).

12. Kobayashi, T.: Jap. Circulat. J. 31: 1285, 1967.

13. Master, A. M.: U.S. Nav. Med. Bull. 40: 346, 1942.

14. Manning, G. W.: Am. Heart J. 54: 823, 1957.

15) Holter, N.J.: Ann. N.Y. Acad. Sci. 65:913, 1957.

16. Takahashi, H., Iwatsuka, T., Ohashi, I., and Hotta, S.: Jap. Heart J. 4: 105, 1963.

17. Abarquez, R. F., Freiman, A. H., Reichel, F., and LaDue, J. S.: Circulation 22: 714, 1960.

18. Blomqvist, G., Astrand, I., Ekblom, B., and Hall, P.: Physical activity and the heart, edited by Karvonen, M. J, and Barry, A.J., Charles C. Thomas, Illinois, p. 134, 1967.

19. Yamada, K., Yamana, K., Mori, S., Teramoto, T., Iwatsuka, T., Okajima, M., Nakayama, R., and Tomita, Y.: Jap. Circulat. J. 21:669, 1958 (in Japanese).

20. Yamada, K., Yamana, K., Mori, S., Teramoto, T., Iwatsuka, T., Okajima, M., Nakayama, R., and Tomita, Y.: Jap. Circulat. J. 22: 6, 1959 (in Japanese). 